\title{
PENGARUH KONTRAK PSIKOLOGIS DAN MOTIVASI KERJA TERHADAP KOMITMEN ORGANISASI GURU SMK NEGERI KABUPATEN LAMPUNG BARAT
}

\author{
Uza Sukmana ${ }^{1}$
}

\begin{abstract}
The objective of this research is to obtain information about the effect of psychological contract and job motivation on teacher organization commitmen. It was quantitative research with survey method in SMK Negeri Kabupaten Lampung Barat. The research was conducted to all teacher of SMK Negeri Kabupaten Lampung Barat by using a survey method with path analysis applied in testing hypothesis. The number 154 teachers as sample was selected by using Slovin formula.The research conlude: (1) There is a direct positive effect of psychological contract on organization commitmen. (2) There is a direct positive effect of job motivation on organization commitmen. (3) There is a direct positive of psychological contract on job motivation.
\end{abstract}

Keywords: psychological contract, job motivation, organization commitmen.

\section{PENDAHULUAN}

Sistem Pendidikan Nasional harus mampu menjamin pemerataan kesempatan pendidikan, peningkatan mutu serta relevansi dan efisiensi manajemen pendidikan untuk menghadapi tantangan sesuai dengan tuntutan perubahan kehidupan lokal, nasional dan global sehingga perlu dilakukan pembaharuan pendidikan secara terencana, terarah dan berkesinambungan.

Untuk meningkatkan mutu pendidikan sangat ditentukan oleh banyak pihak, apakah pemerintah, masyarakat, sekolah, orang tua dan siswa itu sendiri. Idealnya semua instrumen yang terlibat dalam pendidikan, haruslah bekerja secara profesional, jika disebutkan sekolah dan guru sebagai penyebab rendahnya mutu pendidikan kita tentunya akan sepakat, dan sekolah bersama guru akan menerimanya karena guru merupakan pihak yang langsung terlibat dalam interaksi pembelajaran. Di tangan para gurulah masa depan dan pencerdasan negeri ini akan terwujud.

Dua hal yang sangat penting dalam mutu pendidikan adalah proses dan hasil. Proses melibatkan berbagai input seperti; bahan ajar (kognitif, afektif dan psikomotor), metode mengajar, sarana dan prasarana lembaga pendidikan, dukungan administrasi, berbagai sumber daya dan upaya penciptaan suasana yang nyaman untuk belajar. Mutu dalam konteks "hasil pendidikan" mengacu pada prestasi yang dicapai oleh lembaga pendidikan pada setiap kurun waktu tertentu. Dalam UU no. 14 Tahun 2005 tentang guru dan dosen menyatakan bahwa: Guru adalah pendidik profesional dengan tugas utama mendidik, mengajar, membimbing, mengarahkan, melatih, menilai, dan mengevaluasi peserta didik pada pendidikan anak usia dini jalur pendidikan formal, pendidikan dasar, dan pendidikan menengah.

Pendidikan tidak hanya berorientasi pada produk semata, melainkan diukur pada kualitas proses pendidikan. Ketika guru mempunyai komitmen yang tinggi terhadap organisasinya, maka guru akan melakukan apapun untuk memajukan sekolahnya karena keyakinannya terhadap organisasinya.

Sekolah Menengah Kejuruan Khusus SMK Negeri sangat membutuhkan guruguru yang memiliki komitmen tinggi terhadap organisasi, karena guru merupakan

\footnotetext{
${ }^{1}$ Guru IPS di SMP Cendikia Dewantara Cikarang
} 
unsur yang sangat penting dalam mengembangkan pendidikan dan menunjang keberhasilan organisasi. Guru yang memiliki komitmen organisasi tinggi akan merasa menjadi bagian dari organisasi tersebut. sehingga mereka akan bekerja sepenuh hati dengan kesadaran yang tinggi sehingga akhirnya akan mempermudah tercapainya tujuan serta visi dan misi sekolah. Sesuai dengan Kode Etik Guru pasal 6 poin 4 yaitu hubungan guru dengan sekolah dan rekan sejawatnya di mana guru memelihara dan meningkatkan kinerja, prestasi, dan reputasi sekolah.

Kendala Sekolah SMK Negeri di Lampung Barat adalah kekurangan guru, baik guru mata pelajaran maupun guru produktif, ditambah lagi dengan komitmen guru dan profesionalisme guru yang kurang, hal ini terlihat dari buruknya tingkat kehadiran dan ketidak tepatan dalam pembuatan administrasi sekolah serta tidak secara terus menerus. Selain itu ketidak sesuaian pendidikan guru yang mengajar. Sehingga sekarang diberlakukan absensi dengan menggunakan deteksi jari tangan sehingga absensi guru bisa terlihat dari jam kedatangan dan jam pulang mengajar. Selanjutnya banyak guru yang pindah keluar Lampung barat dari sekolah tempatnya mengajar dengan beragam alasan.

Guru SMK Negeri akan memiliki komitmen kerja yang tinggi apabila ditunjang dengan adanya motivasi kerja dan serta tidak dilanggarnya kontrak psikologis guru sehingga guru merasa nyaman dalam bekerja, mampu mengembangkan kreatifitas dalam menjalankan tugas-tugasnya dengan penuh rasa tanggung jawab.

Koordinasi yang baik yang dilakukan oleh sekolah dengan guru di mana sekolah dapat melakukan banyak hal pada guru seperti, memperlakukan guru dengan adil, jaminan kesehatan, pengembangan karir, lingkungan kerja yang menyenangkan. Begitu pun guru bekerja keras, lembur, bekerja dengan baik, membantu rekan kerja sehingga satu sama lain saling memberikan manfaat agar sekolah semakin berkembang. Sehingga akan melahirkan pencapaian tujuan sekolah, serta tujuan dari para individu yang ada di dalam lingkungan sekolah. Di samping itu keterpaduan kerja guru dalam melaksanakan kegiatan pembelajaran serta penciptaan situasi yang kondusif merupakan pra syarat keberhasilan tujuan sekolah. Untuk mencapai tujuan yang telah ditetapkan, diperlukan individu yang memiliki komitmen yang tinggi terhadap organisasi, dedikasi tinggi, profesional serta lingkungan sekolah yang baik.

Dua di antara beberapa faktor lain yang turut menentukan komitmen organisasi adalah motivasi kerja guru dan kontrak psikolagis antara sekolah dengan guru terealisasi dengan baik. Motivasi akan timbul dalam diri guru apabila ada perhatian, kesesuaian, kepercayaan dan kepuasan yang diberikan sekolah, sehingga akan dapat meningkatkan komitmen dan kinerja yang baik. Sebaliknya jika perhatian, kesesuaian, kepercayaan dan kepuasan yang diberikan sekolah kurang maka guru akan sulit untuk termotivasi dalam bekerja sehingga kurang berkomitmen terhadap sekolahnya.

Kontrak psikologis dapat meningkatkan komitmen guru ketika kontrak yang terjadi dapat terealisasi dengan baik antara guru dengan sekolah, dengan kata lain tidak ada pelanggaran kontrak oleh sekolah terhadap guru walaupun kontrak tersebut dalam bentuk tidak tertulis atau non-formal. Sebaliknya ketika terjadi pelanggaran kontrak psikologis oleh sekolah terhadap guru, maka dapat timbul gejala seperti malas bekerja, muncul keluhan-keluhan guru, rendahnya prestasi kerja, indisipliner guru dan gejala negatif lainya.

Memperhatikan kondisi-kondisi yang telah dipaparkan diatas, peneliti memandang perlunya dikaji tentang kontra psikologis dan motivasi kerja terhadap komitmen organisasi guru SMK Negeri di Kabupaten Lampung Barat. 


\section{Komitmen Organisasi}

Secara umum diakui kesuksesan dan kegagalan perusahaan di masa mendatang akan ditentukan oleh komitmen karyawan. Hal ini dikarenakan karyawan yang memiliki komitmen kuat akan lebih mudah diarahkan dan diandalkan dalam menyelesaikan tugas, dengan demikian organisasi akan lebih mudah mencapai tujuan secara efektif dan efisien. Komitmen organisasi merupakan bentuk pengabdian seseorang karena kepercayaannya pada tujuan mulia dari sebuah organisasi di mana dia bernaung. Pengabdian seseorang yang melampaui batas-batas kewajaran dalam sebuah hubungan transaksional antara pekerja dan pemberi kerja. Bahkan cenderung tidak mempedulikan keseimbangan antara apa yang dia terima atas apa yang telah dia kerjakan. Segala kemampuan dia kerahkan demi mencapai apa yang telah dicita-citakan bersama dengan organisasinya.

Dalam hal organisasi sekolah, guru merupakan tenaga profesional yang berhadapan langsung dengan siswa, maka guru dalam menjalankan tugasnya sebagai pendidik mampu menjalankan kebijakan-kebijakan dengan tujuan-tujuan tertentu dan mempunyai komitmen yang kuat terhadap sekolah tempat dia bekerja.

Menurut Meyer dan Allen yang dikutip oleh Colquitt, LePine, dan Wesson (2015:117) menyatakan bahwa: "organizational commitment is defined as the desire on part of an employee to remain a member of the organization", Komitmen Organisasi adalah keinginan karyawan untuk tetap menjadi anggota organisasi.

Lebih jelasnya, Mowday seperti yang dikutip Fred Luthans (2011:147) menjelaskan mengenai Komitmen Organisasi yaitu sebagai berikut: "organizational Commitment is most often defined as (1) a strong desire to remain a member of particular organization; (2) a willingness to exert high levels of effort on behalf of the organization; and (3) a definite belief in, and acceptance of, the values and goal of the organization. In other words, this is an attitude reflecting employees' loyalty to their organization and is an ongoing process through which organizational participants express their concern for the organization and its continued success and well-being". Komitmen organisasi paling sering didefinisikan sebagai (1) keinginan yang kuat untuk tetap menjadi anggota dalam organisasi, (2) kemauan untuk mengerahkan usaha tertinggi untuk kepentingan organisasi, dan (3) keyakinan yang pasti dalam menerima nilai-nilai dan tujuan organisasi. Dengan kata lain, ini adalah sikap yang mencerminkan loyalitas pegawai terhadap organisasi dan merupakan proses yang berkelanjutan di mana peserta organisasi mengekspresikan perhatian mereka terhadap organisasi dan kesuksesan serta kesejahteraannya.

Selanjutnya Ricky W. Griffin and Michael W. Pustay (2014:74) mendefinisikan, "organizational commitment, which reflects an individual's identification with and loyalty to the organization" Komitmen organisasi mencerminkan keberpihakan individu terhadap organisasi tempatnya bekerja dan loyalitas terhadap organisasi.

Berdasarkan konsep-konsep yang telah dideskripsi di atas, dapat disintesiskan bahwa komitmen organisasi adalah keinginan kuat seseorang untuk tetap menjadi anggota atau bagian dari suatu organisasi dengan menunjukan sikap kepedulian, keterlibatan yang tinggi, orientasi intensitas tinggi, dan loyalitas terhadap organisasi guna mewujudkan tujuan organisasi dengan indikator: (1) keinginan untuk tetap menjadi anggota organisasi, (2) kepercayaan terhadap nilai dan tujuan organisasi, (3) penerimaan terhadap organisasi, (4) keterlibatan pada kegiatan organisasi, (5) loyalitas terhadap organisasi.

\section{Kontrak Psikologis}

Istilah kontrak psikologis merupakan kontrak tidak tertulis atau perjanjian tidak 
tertulisa yang bersifat dua arah baik dari karyawan maupun dari organisasi. George dan Jones (2012:248) mengemukakan bahwa, "a psychological contract is an employee's perception of his or her exchange relationship with an organization". Kontrak psikologis adalah persepsi karyawan mengenai hubungan timbal balik dengan organisasi. Hasil perjanjian yang akan disediakan perusahaan kepada karyawan, dan kontribusi yang diberikan karyawan kepada organisasi. Contoh karyawan dapat melakukan banyak hal untuk organisasi, seperti bekerja keras, lembur, bekerja dengan baik, membantu rekan kerja.

Lebih lanjut Guest dalam Michael Armstrong (2009:279) mendefinisikan, "the psychological contract is concerned with assumptions, expectations, promises and mutual obligations. It creates attitudes and emotions which form and govern behaviour". Kontrak psikologis adalah asumsi, harapan, janji-janji dan kewajiban bersama menciptakan sikap dan emosi yang membentuk dan mengatur perilaku.

Shaun Tyson (2006 : 192) berpendapat, "the 'psychological contract' is the term used to describe the 'deal' between employer and employee, not the legal contract, but the bargain implicitly struck about what each party can expect from each other, and about the obligations each has to the other". Kontrak Psikologis adalah kesepakatan antara karyawan dan organisasi serta kesepakatan implisit satu sama lain yang bukan kontrak legal. Diharapkan masingmasing pihak melaksanakan kewajibannya masing-masing. Seperti yang dinyatakan Michael Armstrong, karyawan mungkin berharap diperlakukan adil sebagai manusia, diberikan pekerjaan yang menggunakan kemampuan mereka, diberikan balas jasa yang setimpal dengan kontribusi mereka, dapat berkembang dan menunjukkan kompetensi, memiliki peluang untuk tumbuh lebih lanjut, mengetahui apa yang diharapkan dari mereka dan diberikan umpan balik mengenai bagaimana pekerjaan mereka, sementara perusahaan mungkin berharap karyawan memberi kinerja terbaik mereka atas nama organisasi (menempatkan kepentingan perusahaaan lebih dulu), berkomitmen sepenuhnya terhadap nilai-nilai perusahaan, rela dan loyal, dan meningkatkan kualitas image organisasi di depan pelanggan dan pemasoknya. Dari sini jelas terlihat bahwa masing-masing pihak memiliki kepentingan yang berbeda, yang nantinya berlanjut menjadi aspek-aspek yang ada dalam daftar kontrak psikologis.

Dari deskripsi konsep di atas, dapat disintesiskan kontrak psikologis adalah kesepakatan seseorang terhadap organisasi tentang harapan kedua belah pihak dalam pelaksanaan kewajibannya masing-masing dengan indikator: (1) kewajiban bersama, (2) kepercayaan terhadap janji, (3) kesepakatan dengan organisasi, (4) harapan bersama 


\section{Motivasi Kerja}

Motivasi telah diserap ke dalam bahasa Indonesia yang berasal dari bahasa Inggris motivation, sedangkan motivation tersebut yang berasal dari bahasa latin movere, yang artinya menggerakkan/ dorongan/ pindah (to move). Dalam kaitannya dengan hal tersebut bahwa sebagai makhluk sosial yang memiliki perasaan, manusia selalu berusaha untuk memenuhi kebutuhannya. Dari dorongan-dorongan tersebut muncullah tindakan yang terarah, selanjutnya orang menyebut dorongan itu sebagai suatu motif. Dengan motif orang tergerak untuk melakukan sesuatu sehingga arah dan tujuan hidupnya dapat tercapai. Apabila tujuan, impian dan harapannya tercapai seseorang akan merasa gembira, tenang dan damai. Untuk dapat meningkatkan dirinya seorang guru memerlukan tujuan atau harapan, baik tujuan jangka pendek maupun tujuan jangka panjang. Dengan tujuan tersebut seorang guru menjadi termotivasi dalam usaha atau kerjanya. John W. Newstrom (2011:109), mendefinisikan bahwa, "work motivation is the result of a set of internal and external forces that cause and employee to choose an appropriate course of action and engage in certain behaviors." Motivasi kerja adalah seperangkat hasil dari dorongan internal dan external yang menyebabkan pegawai memilih jalan pada tindakan dan mengikutsertakan dalam perilaku. Idealnya perilaku ini akan diwujudkan dalam bentuk prestasi untuk mencapai tujuan organisasi.

Kemudian Ruth Kanfer, Gilad Chen, dan Robert D. Pritchard (2008:3) mendefinisikan adalah, "work motivation is commonly defined as the psychological processes that determine (or energize) the direction, intensity, and persistence of action within the continuing stream of experiences that characterize the person in relation to his or her work." Motivasi kerja biasanya didefinisikan sebagai proses psikologis yang menentukan (memberi kekuatan) pada arah, intensitas dan ketekunan dalam bertindak yang dipadukan dengan pengalaman yang dimiliki oleh seseorang dalam hubungannya dengan pekerjaannya. Dengan pengalaman yang dimiliki seseorang dalam bekerja akan memudahkan organisasi untuk mengarahkan pada tujuan organisasi.

Lebih lanjut Jennifer M. George \& Gareth R. Jones,(2012:175) bahwa, "work motivation is the psychological forces within a person that determine the direction of the person's behavior in an organization, the person's level of effort, and the person's level of persistence in the face of obstacles. Motivation is distinct from performance; other factors besides motivation (for example, ability and task difficulty) influence performance." Motivasi kerja adalah kekuatan psikologis dari dalam diri yang mendorong seseorang dalam menentukan arah melalui perilaku seseorang dalam organisasi, tingkat usaha, dan daya juang dalam menghadapi rintangan. Motivasi merupakan pembeda terhadap hasil kerja, di samping faktor-faktor lain (sebagai contoh kemampuan dan tugas yang berat dapat mempengaruhi kinerja). Pada dasarnya sekolah bukan saja mengharapkan guru yang mampu, cakap dan terampil, tetapi yang terpenting mereka mau bekerja giat dan berkeinginan untuk mencapai hasil kerja yang optimal. Kemampuan, kecakapan dan keterampilan guru tidak ada artinya bagi lembaga pendidikan jika mereka tidak mau bekerja keras dengan menggunakan kemampuan, kecakapan dan keterampilan yang dimilikinya. Motivasi penting karena dengan motivasi ini diharapkan setiap individu mau bekerja keras dan antusias untuk mencapai produktivitas kerja yang tinggi.

Kanfer sebagaimana dikutip George \& Jones, (2012:181-182)menjelaskan bahwa, "the psychological forces within a person that determine the direction of the person's behavior in an organization, effort level, and persistence in the face of obstacle". Motivasi kerja didefinisikan sebagai kekuatan psikologis di dalam diri seseorang yang menentukan 
arah perilaku di dalam organisasi, tingkat upaya dan ketekunan dalam menghadapi rintangan.

Berdasarkan konsep-konsep yang telah dideskripsi di atas, dapat disintesiskan bahwa motivasi kerja adalah dorongan dari dalam dan dari luar individu untuk mencapai hasil kerja yang lebih baik dengan indikator: (1) usaha untuk bekerja, (2) ketekunan dalam melaksanakan tugas, (3) dorongan untuk bekerja, dan (4) tanggung jawab.

\section{METODE PENELITIAN}

Penelitian ini dilaksanakan di SMK Negeri Kabupaten Lampung Barat. Pendekatan penelitian dilakukan secara kuantitatif, dengan metode survey, diukur menggunakan instrumen kuisioner. Analisis data menggunakan statistik parametris dengan path analysis. Penelitian ini dilaksanakan kepada para guru SMK Negeri Kabupaten Lampung Barat yang berjumlah 248 guru dengan jumlah sampel 154 guru. Data dikumpulkan dengan menggunakan instrumen berupa kuisioner yang telah diuji validitas dan reliabilitasnya. Berdasarkan hasil uji instrumen tersebut, variabel komitmen organisasi terdiri dari 32 item pernyataan valid dengan reliabilitas 0,944. Variabel kontrak psikologis terdiri 31 item pernyataan valid dengan reliabilitas 0,950. Variabel motivasi kerja terdiri 32 item pernyataan valid dengan reliabilitas 0,938. Sehingga disimpulkan memenuhi syarat untuk dijadikan pengukur variabel penelitian.

\section{HASIL PENELITIAN DAN PEMBAHASAN}

\section{Pengaruh Kontrak Psikologis terhadap Komitmen Organisasi}

Dari hasil pengujian hipotesis pertama dapat disimpulkan bahwa terdapat pengaruh langsung positif Kontrak Psikologis terhadap Komitmen Organisasi dengan nilai koefisien korelasi sebesar 0,391 dan nilai koefisien jalur sebesar 0,283. Ini memberikan makna Kontrak Psikologis berpengaruh langsung positif terhadap komitmen organisasi.

Hasil penelitian ini senada dengan pendapat beberapa ahli diantaranya adalah pendapat Laurie J. Mullins (2006:772) menjelaskan, "good people management practices, a positive psychological contract and a supportive organisation culture lead to commitment, job satisfaction and a willing contribution from employees. These characteristics positively feed through to higher productivity and profitability". Praktek manajemen yang baik, kontrak psikologis yang positif dan budaya organisasi yang mendukung menyebabkan komitmen, kepuasan kerja dan kesediaan keterlibatan dari karyawan. Karakteristik ini positif memberikan produktivitas yang lebih tinggi dan keuntungan.

Selanjutnya Michael Armstrong (2008:109) menjelaskan, "the organization attracts such people by being 'the employer of choice'. It retains them by providing better opportunities and rewards than others and by developing a positive psychological contract that increases commitment and creates mutual Trust". Organisasi menarik orang / pegawai seperti dengan menjadi bagian dalam perusahaan pilihannya. Ini mempertahankan mereka dengan memberikan kesempatan yang lebih baik dan manfaat dari yang lain dan dengan mengembangkan kontrak psikologis positif sehingga meningkatkan komitmen dan menciptakan rasa saling percaya.

Kontra k psikologis memberikan pengaruh terhadap komitmen organisasi sebagaimana yang dijelaskan oleh McShane dan Von Glinow (2011:104), "organizational commitment is strongly influenced by the psychological contract". Dapat diartikan bahwa komitmen organisasi sangat dipengaruhi oleh kontrak psikologis. 
Berdasarkan uraian di atas jelaslah bahwa kontrak psikologis berpengaruh langsung positif terhadap komitmen organisasi.

\section{Pengaruh Motivasi Kerja terhadap Komitmen Organisasi}

Dari hasil pengujian hipotesis kedua dapat disimpukan bahwa terdapat pengaruh langsung positif Motivasi Kerja terhadap Komitmen Organisasi dengan nilai koefisien korelasi sebesar 0,390 dan nilai koefisien jalur sebesar 0,281. Ini memberikan makna Motivasi Kerja berpengaruh langsung positif terhadap komitmen organisasi.

Hasil penelitian ini senada dengan pendapat beberapa ahli diantaranya John A. Wagner dan John R. Hollenbeck (2010:116) menjelaskan bahwa "empowered workers feel that they can display their competence and make a positive impact on the world or at least their little corner of it. This belief, in turn, creates a high level of intrinsic motivation that results in high job performance and organizational commitment". Pekerja diberdayakan merasa bahwa mereka dapat menampilkan kompetensi mereka dan membuat dampak positif pada dunia atau setidaknya sudut kecil mereka itu. Keyakinan ini, pada gilirannya, menciptakan tingkat tinggi motivasi intrinsik yang menghasilkan prestasi kerja yang tinggi dan komitmen organisasi.

Selanjutnya Jason A. Colquitt, Jeffery A. Lepine dan Michael J. Wesson (2015: 189) menjelaskan, "less is known about the effects of motivation on commitment. however, equity has a moderate positive effect. people who experience higher levels of equity tend to feel higher levels of affective commitment and higher levels of normative commitment. effects on continuance commitment are weaker". Sedikit yang diketahui tentang efek motivasi pada komitmen. Namun, ekuitas memiliki efek positif moderat. orang yang mengalami tingkat yang lebih tinggi dari ekuitas cenderung merasa tingkat yang lebih tinggi komitmen afektif dan tingkat yang lebih tinggi dari komitmen normatif. Efek pada komitmen kontinyu lebih lemah.

Berdasarkan uraian di atas jelaslah bahwa motivasi kerja berpengaruh langsung positif terhadap komitmen organisasi.

\section{Pengaruh Kontrak Psikologis terhadap Motivasi Kerja}

Dari hasil pengujian hipotesis ketiga dapat disimpulkan bahwa terdapat pengaruh langsung positif Kontrak Psikologis terhadap Motivasi Kerjadengan nilai koefisien korelasi sebesar 0,386 dan nilai koefisien jalur sebesar 0,386. Ini memberikan makna Kontrak Psikologis berpengaruh langsung positif terhadap Motivasi Kerja.

Hasil penelitian ini senada dengan pendapat para ahli diantaranya Laurie J. Mullins (2006:187) menjelaskan, "one of the strongest influences on people's level of motivation is attitudes and expectations. In addition to the above categories, the motivation to work is also increasingly influenced by the changing nature of the work environment and the concept of the "psychological contract" Salah satu pengaruh kuat dalam tingkat motivasi masyarakat adalah sikap dan harapan. Selain kategori di atas, motivasi kerja juga semakin dipengaruhi oleh sifat perubahan lingkungan kerja dan konsep kontrak psikologis.

Michael Armstrong (2009:24) menjelaskan bahwa, "the development of a positive psychological contract and means of inceasing themotivation and commitment of employees". Pengembangan kontrak psikologis yang positif dan berarti meningkatkan motivasi dan komitmen pada karyawan.

Evan M. Bermen (2006:141) menjelaskan bahwa, "beyond this, managers increase motivation by creating mutual understandings (psychological contracts) with workers. Through such understandings, workers and employers are better able to align their needs, and provide a structure for discussion when potentially demotivating or unproductive circumstances arise." 
Manajer meningkatkan motivasi dengan menciptakan pemahaman bersama (kontrak psikologis) dengan pekerja. Melalui pemahaman tersebut, pekerja dan pengusaha lebih mampu menyelaraskan kebutuhan mereka, dan manajer menyediakan ruang diskusi ketika keadaan pekerja berpotensi kurang termotivasi atau tidak produktif muncul.

Berdasarkan uraian di atas jelaslah bahwa kontrak psikologis berpengaruh langsung positif terhadap motivasi kerja.

\section{PENUTUP}

Kesimpulan: Berdasarkan hasil dan analisis data, maka dapat diambil kesimpulan: (1) Kontrak psikologis berpengaruh langsung positif terhadap komitmen organisasi. Artinya ketepatan kontrak psikologis yang dilaksanakan sekolah mengakibatkan peningkatan komitmen organisasi para guru SMK Negeri di Kabupaten Lampung Barat: (2) Motivasi kerja berpengaruh langsung positif terhadap komitmen organisasi. Artinya peningkatan motivasi kerja mengakibatkan peningkatan komitmen organisasi para guru SMK Negeri di Kabupaten Lampung Barat: dan (3) Kontrak psikologis berpengaruh langsung positif terhadap motivasi kerja. Artinya ketepatan kontrak psikologis yang dilaksanakan sekolah mengakibatkan peningkatan motivasi kerja para guru SMK Negeri di Kabupaten Lampung Barat.

Saran: Berdasarkan kesimpulan di atas, maka saran yang perlu ditindak lanjuti antara lain: (1) Bagi Dinas Pendidikan Kabupaten Lampung Barat selaku pemegang kebijakan, merealisasikan semua janji yang telah diprogramkan, mengevaluasi sistem yang telah diimplementasikan sampai di mana janji-janji yang dibuat dengan sekolah terpenuhi, sehingga harapan sekolah dan para guru terpenuhi, (2) Sekolah dalam hal ini kepala sekolah sebagai pemegang kebijakan agar melaksanakan janji-janji yang telah dibuat terhadap para guru sehingga guru semangat dan fokus untuk bekerja dan menjalankan tugas sesuai tujuan sekolah yang telah dibuat. Melibatkan dan memberikan tanggung jawab kepada para guru untuk ikut mengelola manajemen sekolah, sehingga para guru merasa memiliki dan merasa diakui keberadaannya di dalam sekolah, (3) Guru sebagai salah satu elemen terpenting maju tidaknya pendidikan di sekolah sudah sepatutnya menyadari dan mengerti makna dan hakikat serta melaksanakan tugas dan tanggung jawabnya sebagai pendidik. Profesionalisme dan komitmen yang tinggi terhadap majunya pendidikan harus tertanam kuat di dalam diri para guru demi tercapainya mutu pendidikan yang lebih baik, (4) Bagi peneliti lain agar dapat dijadikan sebagai referensi dalam rangka penelitian lanjutan terkait dengan masalah kontrak psikologis, motivasi kerja dan komitmen organisasi. Selain itu dapat memperluas penelitian dengan menambahkan variabel lain yang mempengaruhi komitmen organisasi misalnya budaya organisasi, iklim organisasi.

\section{DAFTAR RUJUKAN}

Armstrong, Michael. A Handbook of Human Resource management Practice tenth edition. London: Kogan page, 2009.

Berman, Evan M. Performance and productivity in public and nonprofit Organization 2 nd ed. USA: M.E. Sharpe, Inc., 2006. 
Colquitt, Jason A., Jeffery A. Lepine dan Michael J. Wesson. Organizational Behaviour: Improving, Performance and Commitment in the Workplace (New York : McGraw-Hill, 2015).

George, Jennifer M. and Gareth R. Jones. Understanding and Managing Organizational Behavior Sixth Edition, New York, Prentice Hall, 2012.

Griffin, Ricky W. Gregory Moorhead. Organizational Behavior: Managing People and Organizations, Eleventh Edition. South-Western, Cengange Learning, 2014.

Kanfer, Ruth. Gilad Chen \& Robert D. Work Motivation: Past, Present, and Future. (New York: Taylor \& Francis Group, LLC., 2008).

Laurie J. Mullins. Essentials Of Organisational Behaviour Seventh Edition. England : Prentice Hall, 2006.

Luthans, Fred. Organizational Behavior An Evidence-Based Approach Twelfth Edition. New York: McGraw-Hill Companies Inc., 2011.

McShane, Steven L dan Mary Ann Von Glinov. Organizational Behaviour 4th Edition. New York: McGraw-Hill, International Edition, 2011.

Newstrom, John W. Human Behavior at Work (New York : McGraw-Hill Companies. Inc., 2011.

Tyson, Shaun. Essentials of Human Resource Management Fifth Edition USA: Elsevier Ltd., 2006.

Wagner, John A. dan John R. Hollenbeck. Organizational behavior : securing competitive advantage. New York : Routledge, 2010. 